\title{
Meaning Making, Uncertainty Reduction, and Autobiographical Memory: A Replication and Reinterpretation of the TALE Questionnaire
}

\author{
Orlando J. Olivares \\ Bridgewater State University, Bridgewater, USA \\ Email: oolivares@bridgew.edu \\ Received October $4^{\text {th }}, 2011$; revised November $14^{\text {th }}, 2011$; accepted December $16^{\text {th }}, 2011$
}

\begin{abstract}
The present research was guided by two primary goals: 1) replicate the empirical structure of the Thinking about Life Experiences (TALE) questionnaire (Bluck, Alea, Habermas, \& Rubin, 2005); and 2) explore how the functions of autobiographical memory may interact and support one another. Toward the second goal, it is suggested that the potential functions of autobiographical memory may be understood from an existential framework that is grounded by two principles: humans are driven by a need for meaning and meaning is found in relation to others and other things in the world. In this pursuit of meaning making, and a desire to know what to expect from the world, humans seek to create a coherent set of relations among the various existential elements in their lives (Heine, Proulx, \& Vohs, 2006); accordingly, humans strive to reduce uncertainty about the world and their place in it. As such, the TALE was reinterpreted using a relational framework and a 28-item self-report measure was developed. Participants completed the TALE and the reinterpreted TALE (RTALE). The results provide some support for the 3-factor structure of the TALE. The proposed 4-factor structure of the RTALE was supported.
\end{abstract}

Keywords: Autobiographical Memory; Meaning Making; Uncertainty Reduction

\section{Introduction}

There has been a fairly robust theoretical literature on the function of autobiographical memory (AM), although the empirical literature has been very limited. For instance, Bluck, Alea, Habermas, and Rubin (2005) stated that: "Only three projects, however, have examined the functions of AM empirically (Hyman \& Fares, 1992; Pasupathi, Lucas, \& Coombs, 2002; Walker, Skowronski, Gibbons, \& Vogl, 2003¹)” (p. 94). Moreover, the empirical frameworks used in these studies have mirrored the theoretical literature; that is, the AM literature was used to inform the putative structure and function of AM. Bluck et al. (2005), for example, developed a self-report questionnaire (Thinking About Life Experiences, TALE) to empirically assess three functions of AM that have been consistently and widely reported: self, directive, and social functions. These theoretical functions were empirically supported by Bluck et al. (2005).

Considering the paucity of the empirical literature, one goal of the present research is to replicate the empirical structure of the TALE. Also, Pillemer (2003), in ideas for new research, suggested that: "Because directive, self, and social functions of autobiographical memory are intimately connected in everyday activities, a prime topic for new research is how they interact, support, or impede each other” (p. 200). Accordingly, a second

\footnotetext{
${ }^{1}$ In Bluck et al. (2005) this article was referenced as "Manuscript submitted for publication”. This article, however, was not published. Email communication with the primary author indicated that "Elements of the paper you referenced can be found in the following items. I especially suggest the Skowronski \& Walker (2004) article: Skowronski, J. J., \& Walker, W. R. (2004). How describing autobiographical events transform autobiographical memory. Social Cognition, 22, 555-590.”
}

goal of the present research is to explore how the AM functions may interact and support one another. Using an existential framework, it will be argued that meaning making is a central concern of AM functions; moreover, it is suggested that meaning making develops in the context of relational frameworks and in response to uncertainty reduction (Bruner \& Postman, 1949; Yost, Strube, \& Bailey, 1992).

In this paper, meaning making is conceptualized as making sense of relations, that is, meaning is found in relations (Camus, 1955), for example, self-self relations, self-other relations, and self-event relations. Moreover, it will be argued that humans are driven to create a coherent set of relations among the various existential elements in their lives (Pasupathi, Mansour, \& Brubaker, 2007). In this pursuit of meaning making, and a desire to know what to expect from the world (cf. Swann, 1987: p. 1038), humans are driven to reduce uncertainty about the world and their place in it (Smith, Hogg, Martin, \& Terry, 2007); accordingly, they will seek to reduce or remove: dissonant representations of events (Festinger, 1957) or stimuli (Bruner \& Postman, 1949); inconsistencies in perceptions of self (Pasupathi, Mansour, \& Brubaker, 2007; Yost et al., 1992); schema inconsistent information (Pasupathi, 2001); disconfirming information about self-conceptions (Swann, 1987; Swann, Pelham, \& Krull, 1989); and unstable interpersonal relationships (Heine, Proulx, \& Vohs, 2006). In sum, humans are driven to reduce uncertainty in their relational frameworks (Smith et al., 2007). Thus, uncertainty reduction will be considered a primary psychological mechanism that underlies and serves meaning making; as such, it is proposed that uncertainty reduction is an AM function, and the TALE will be reinterpreted in the context of uncertainty reduction and meaning making (see Figure 1). 


\section{O. J. OLIVARES}

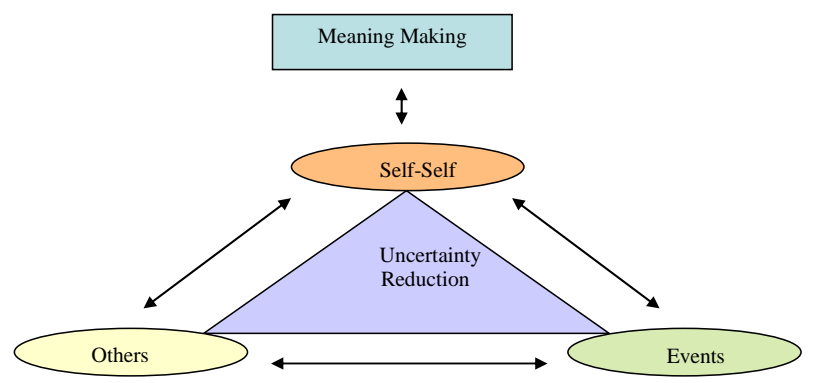

Figure 1.

Meaning making, uncertainty reduction and the functions of AM: A relational framework.

First, this study will provide a brief overview of the TALE and the functions it represents. Next, an existential framework will be used to explore meaning making: the AM functions will be discussed within this context. Finally, meaning making will be examined in the context of uncertainty reduction and a reinterpretation of the TALE will be proposed. It will be shown that TALE items with the highest factors loadings are imbued with lexical content that speaks to uncertainty reduction within a relational context. Specifically, it will be argued that people are meaning makers, motivated by a need to develop and maintain a coherent pattern of structural relations; central to the process of meaning making is uncertainty reduction.

\section{The TALE and Functions of AM}

The TALE suggests that AM serves three functions: directive, self, and social; yet, there were some minor variations on the original conceptualizations of the three functions. The original TALE consisted of 28 items: 10 directive items; 10 self items; and 8 social items. In the final analysis the TALE consisted of 24 items: 14 directive items, 4 self items, and 6 social items.

\section{The Directive Function}

Consistent with the theoretical literature, the TALE found that the directive function aids in problem solving (Cohen, 1998), predicting future events (Lockhart, 1987), and guiding goal-directed behavior (Conway, 2003). Bluck et al. (2005), however, found that the directive function took on a broader function than originally conceptualized. Indeed, originally the TALE directive function had 10 items; in the final analysis it had 14 items, losing 2 items (i.e., these 2 items did not have meaningful factor loadings) and gaining 6 items: 5 items from the self function and 1 item from the social function. Interestingly, one of the items lost was number 2: "When I want to make plans for the future". Nonetheless, the directive function was found to be broader than originally thought and consisted of 14 items: the expanded function seemed to be consistent with not only problem solving and goal-directed behavior, but also making sense of the past to guide present and future behaviors, that is, autobiographical reasoning.

\section{The Self Function}

The theoretical literature suggested that the self function was rather broad, subsuming affect regulation (Pasupathi, 2003), meaning making (McLean, 2005), and developing and maintaining a coherent sense of self, or self-continuity (Barclay,
1996; Fivush, 1998; Wilson \& Ross, 2003). Like the directive function, the self function originally had 10 items. Analyses suggested that the self-function was better represented by 4 items and focused on self-continuity, "the most commonly referred to self function in the literature" (Bluck et al., 2005: p. 109). One of the 10 items, item 8 ("When I want to remember how others have reacted to me in the past in order to decide how to act now"), did not load on any factor; and 5 items loaded on the directive function.

\section{The Social Function}

The social function was reduced to 6 items from 8 . Item 23, "When I want to introduce myself to people or to tell others more about me", did not load on any factor. Item 21, "When I want to make myself feel better by talking to others who have had similar past experiences", loaded on the directive function. Also, the factor analytic results suggested that the social function was better represented by two functions: developing relationships and nurturing relationships (Bluck et al., 2005). Yet, Bluck et al. (2005) suggested that these findings be interpreted with caution for two reasons: 1) the two functions are conceptually similar; and 2) there were only three items that represented each factor. In general, it was thought "that the most central social function of AM is social bonding in existing relationships” (Bluck et al., 2005: p. 111).

In sum, the TALE suggests that AM has three functions: meaning making or sense making (directive), self-continuity (self), and social bonding (social). Fifty-eight percent (14/24) of the TALE items were represented by the directive function and this function accounted for approximately $30 \%$ of the variance. Approximately 17 percent of the TALE items (4/24) were represented by the self function and this function accounted for $7 \%$ of the variance. Twenty-five percent $(6 / 24)$ of the items were represented by the social bonding function and explained about $12.5 \%$ of the variance.

Whether the respective factor loadings are an artifact of the way in which the items were written, are sample specific, or indeed accurately represent the influence of the respective functions of AM, is an empirical question. We do know, however, that the items were originally written in order to provide relatively equal item weightings across functions and reflect the AM literature; yet, the responses to the items resulted in a different set of weightings and revealed some interesting insights about the lexical content of the items and the factors upon which they loaded. One goal of the present research is an attempt to replicate the factor structure of the TALE, thereby shedding light as to the nature of the structure and function of AM. More generally, however, there is a need to better understand the underlying processes that have produced the factor loadings, explore how the AM functions support and interact with one another, and consider other potential functions of AM.

Considering the nascent state of the AM empirical research, it is both reasonable and economical that researchers would look to the (AM) theoretical literature to guide their empirical investigations. However, looking outside the AM literature may provide valuable, novel, and interesting insights regarding the functions of AM. This study will look to the literature on existentialism (e.g, Camus, 1955; Binswanger, 1958; Heidegger, 1953/1996; Koole, Greenberg, \& Pyszczynski, 2006), meaning making (e.g., Bruner \& Postman, 1949; Heine et al., 2006; Schwandt, 2005), and social cognition (e.g., Baumeister, Tice, 
\& Hutton, 1989; Swann, 1987; Swann et al., 1989 ) for insights; yet, the empirical findings of Bluck et al. (2005) and the AM literature will serve as key guideposts in this exploration.

\section{Existential Psychology and Meaning Making: A Relational Framework}

Functional theories of AM suggest that memory serves some purpose, that is, people use memories for some adaptive purpose in everyday life (Bluck et al., 2005). Just as William James (1890) suggested that consciousness evolved to serve particular functions, like guiding the activities of the individual, memories serve an adaptive role. Thus, memories may serve to form meaning for the individual (Conway, 2003), and meaning making may be a way in which AM represents and integrates experiences in some causally coherent fashion (Habermas \& Bluck, 2000). In this article it is suggested that AM represents reality (experiences) with a certain degree of accuracy (Conway, 2003) and seeks to make sense of experiences by forming mental representations of relations that tie together various elements - for example, elements of the self, the self to others, and the self to the external world-such that a coherent meaning-ness is created (Heine et al., 2006). Thus, potential functions of AM may be understood in the context of a need for meaning and the literature that most directly explores this concept, a pursuit of meaning, is existentialism.

Existentialism is grounded by two principles: 1) humans are driven by a need for meaning making or sense making (Koole et al., 2006); and 2) and meaning is found in relationship to others and other things in the world (Heidegger (1953/1996)). Heidegger stated: “...Being-in is thus the formal existential expression of the being of Da-sein which has the essential constitution of being-in the-world” (p. 51, emphasis in the original). Binswanger (1963) noted that man is communal and existence involves interactions with other people. Specifically, Binswanger (1958) expounded on Heidegger's "being-in-the-world" as the structure of meaningful relationships in which there are three modes of world. Eigenwelt is the "own-world" or one's relationship to one's self. Mitwelt is the "with-world" or one's social world. Umwelt is the "world-around" or one's environment. Thus, humans are meaning-makers driven by the need to make and understand relations within socially constructed realities.

Meaning making can be considered a process that uses prior knowledge to assign meaning to new information (Schwandt, 2005). Thus, fundamentally, meaning making is about making sense of that which is unknown, not understood, or, more simply, that which is imbued with uncertainty, for example, one's identity, how one connects to others, or how one fits into the world (Koole et al., 2006). Schwandt (2005) suggests that meaning making requires 3 components. One component includes stimuli or information from the environment that suggests meaning is required, for example, "I failed to make my varsity high school basketball team” (e.g., Pillemer, 2003: p. 196). A second component is a knowledge structure that serves as a framework for understanding. Bruner and Postman (1949) refer to this template of understanding as "directive factors" that serve to organize one's perceptual field. Thus memories may provide scripts for how to respond to a novel event. A third factor serves to link the new information to the knowledge framework. According to Schwandt (2005), these three processes result in meaning, and meaning is assigned only after a stimulus, event, or experience occurs.

The description of the meaning making process seems to be consistent with the directive function of AM; however, I would argue that since meaning making is about relations and how relations are integrated in some coherent way, then meaning making is embedded within each AM function and also found in the connectedness of the directive, social, and self functions of AM. Pillemer (2003) suggests that directive functions are not secondary in importance to self and social functions but are perhaps the most basic function served by AM. The self function, for example, is concerned with: who am I now; if I have changed, how have I changed; and how have I stayed the same over time (Bluck et al., 2005). The self function is concerned with making sense of who am I and how do I fit into the world - this is a basic existential concern of self-identity (Koole et al., 2006). The social function is concerned with learning about others' lives and forming new relationships. This process suggests that humans have a desire to bridge subjective worlds, to understand the subjective experiences of others, and to develop socially coherent relationships. The social function is concerned with making sense of one's "mitwelt" and the phenomenon known as I-sharing, that is, sharing one's subjective experiences (Pinel, Long, Landau, Alexander, \& Pyszczynski, 2006), and is consistent with the basic existential concern of isolation (Koole et al., 2006). Heine et al. (2006) note the following: "People are meaning-makers insofar as they seem compelled to establish mental representations of expected relations that tie together elements of their external world, elements of the self, and most importantly, bind the self to the external world” (p. 89).

Experimental existential psychology (XXP) suggests that meaning making arises from four basic existential concerns: identity, isolation, death, and freedom. Koole et al. (2006) note that: "In a world where only the real certainty is death, where one can never fully share one's experiences with others, where one's identity is uncertain, and where one is prodded by external forces while facing a new and bewildering array of choices, what meaning does life have?” (p. 214). Thus, from these existential concerns comes the need or motivation for meaning making; this, however, does not suggest that the existential concerns are merely expressions of meaning; rather, the need for meaning is an inextricable part of each existential concern.

\section{Meaning Making and Uncertainty Reduction}

The foregoing analysis suggests that meaning making is a central component of existentialism and the existential concerns; it is also suggested that the potential functions of AM may be understood in the context of meaning making; moreover, it could be reasonably suggested that meaning making may be a bona fide function of AM; that is, one overarching function of AM may be to create meaning in one's life, or to make sense of one's life, for example, "Who am I and how do I fit into this world?" However, given that meaning is understood in the context of relations, meaning making is embedded within the relational structures that people create, and, perhaps, more importantly the perceptions about these relational structures (e.g., Baumeister, Campbell, Krueger, \& Vohs, 2003; Bruner \& Postman, 1949; Swann, 1987).

Meaning is relation (Camus, 1955) and people seek coherent relational structures. Humans are meaning makings who seek to perceive stimuli (e.g., events, experiences) such that they see 
patterns even if they don't exist (Heine et al., 2006), ward of the perception of the unexpected (McGregor, 2006), and seek constancy in their environment (Bruner \& Postman, 1949). Simply put, humans are driven to minimize uncertainty in their relational structures (Bruner \& Postman, 1949; Heine et al., 2006; Yost et al., 1992) ${ }^{2}$. Bruner and Postman (1949) empirically showed how people will seek to minimize percepts that are inimical to that which is expected, that is, people will seek to minimize incongruity because incongruity is a violation of expectation; put differently, incongruity heightens uncertainty. Rogers (1980) suggested that people seek to minimize the gap between their self-concept and reality or between one's selfconcept and their experiences: he called this gap incongruence. Likewise, Swann's (1987) self-verification theory suggests that people will seek self-consistency and have a desire to preserve their self-conceptions: thus they will seek information that confirms their beliefs about who they are; self-confirming information fosters existential security. Heine et al. (2006) suggest that people pursue the maintenance of self-esteem such that deviations from a desired level of self-esteem are considered a threat, and methods to minimize the deviations from desired levels of self-esteem are enlisted. Dunning (2003), for example, found that those provided failure feedback will enlist self-affirming definitions of personality. In short, people seek relational coherence and resist or minimize those environmental stimuli that are inconsistent or incongruent with expected relations that integrate: elements of the self (eigenwelt), the self to the world (umwelt), and the self to others (mitwelt). Thus, meaning making occurs in response to uncertainty reduction about relational structures.

\section{The AM Literature and Uncertainty Reduction}

The construction of autobiographical narratives or life stories is driven by a need for coherence or consistency between aspects of the self and experiences (McLean 2005; Pasupathi, 2001; Pasupathi et al., 2007; Pillemer, 2001; Wilson \& Roth, 2003). Pillemer (2001), for example, discussed four general functional categories of personal event memories: turning points; and originating, anchoring, and analogous events. Originating events and turning points convey a sense of causal coherence; that is, they facilitate the construction of a consistent and purposeful life story. Anchoring events provide affirmation of who one is and a reminder of how the world works, while analogous events provide a guide for how one should behave in the future based on a previous similar situation. Each functional category acts to stabilize, delimit, or affirm one's self-concept. The functional categories, then, do not make one's life more entropic; rather the directive functions serve to decrease the instability and uncertainty in one's life, thereby creating a sense of purpose, consistency, and causal coherence.

McLean (2005), in a sample of 185 college students, suggests that self-defining memories are those that are self-con-

\footnotetext{
${ }^{2}$ Uncertainty is an ambiguous construct; however, uncertainty can be conceptualized as deviations from what is expected; uncertainty connotes unreliability, unpredictability, inconsistency, and incongruity; and from the literature on stress and coping, uncertainty can be defined as a stimulus variable that is threatening, particularly when the occurrence of this threat is unknown or unpredictable (Monat, Averill, \& Lazarus, 1972). Relational uncertainty produces considerable anxiety and psychological discomfort (Gray \& McNaughton, 2000); thus, adaptive efforts occur in anticipation of the unknown events (or threats), for example, avoidance behavior (Lazarus, Averill, \& Opton, 1970).
}

firming. Wilson \& Roth (2003) argue that people seek information that helps to establish a consistent self-identity over time; that is, people seeking self-confirming information when constructing their identity. Seeking confirming evidence precludes the development of uncertainty (Kahneman \& Tversky, 1973). Pasupathi (2001) suggests that once people develop a socially acceptable version of their past, subsequent recollections will be consistent with that version (p. 658). In recounting events people rely on schema consistent information, thereby minimizing the probability that schema inconsistent information will be used. Conflicting mental representations of events produce psychological discomfort (Festinger, 1957); thus, people will seek information that is consistent with preconceived past events and will dismiss or minimize information that is inconsistent with past events (Bruner \& Postman, 1949). In short, seeking evidence to confirm preconceived or existing schemas of self, and of relational frameworks, is one way in which uncertainty is reduced and causal coherence is produced.

Pasupathi et al. (2007) considers the development of the life story in the context of self-event connections. Five different self-event connections were examined across ten different events and multiple studies and samples. One self-event connection provided no connection between an event and the self, although it constituted the majority of the narratives of the study, as such the four other self-event connections will be discussed.

Two self-event relations were found to construct a stable sense of self, "explain" and "dismiss" relations; two self-event relations were found to engender self-continuity, "cause” and "reveal" relations. Dismiss relations rejected experiences that raised (typically negative) implications for the self (p. 96). Dismiss relations are often explained away as "a first and last time event”, or attribute one's behavior to a unique situation or mitigating circumstances. Thus, dismiss relations explain away events that press one toward an unstable and uncertain self. Explain events perpetuate the stability of self by causing events to occur that then reinforce one's self-identity.

Cause relations and revelations induce changes in the self, but they do it in such a way that experiences initially viewed as dissonant with one's self view are rendered consonant. Reveal relations, for example, indicate that an experience will reveal a quality that was previously unrecognized. People will then change their perceptions of the stimulus event such it is consistent with their new vision of who they are. Cause relations are future looking in that experiences cause the self-view to change and, (as a result of the new self), for one's new life story to look different; however, it does not require that one recount experiences that are inconsistent with the new self, but rather to engender continuity of the self.

\section{The TALE and Uncertainty Reduction}

An examination of the highest loading ( ) items from the TALE suggests an attempt to make sense about various relations through uncertainty reduction (see Table 1). For each function, the two items with the highest loadings will be examined. Also, the target of understanding or meaning making will be identified, that is, self, others, or events; yet, it is maintained that meaning making and uncertainty reduction occur in the context of relational structures.

Directive function. Item 11 (.68) for the directive function suggests uncertainty about a relation between self and an event: 


\section{O. J. OLIVARES}

Table 1.

TALE Items form Bluck et al. (2005); Table 2, p. 101, with factor loadings in ( ).

\begin{tabular}{lc}
\hline \multicolumn{1}{c}{ Item } & Directive Function \\
\hline Q11) Integrate unexpected & $(.68)$ \\
Q6) Life choice & $(.66)$ \\
Q5) Learn from error & $(.64)$ \\
Q20) What caused this & $(.58)$ \\
Q4) Face challenge & $(.57)$ \\
Q7) Problem solving & $(.56)$ \\
Q1) Learn lesson & $(.55)$ \\
Q18) Reinterpret past event & $(.54)$ \\
Q9) Recall advice & $(.53)$ \\
Q10) Know problem & $(.50)$ \\
Q19) Feel better & $(.49)$ \\
Q15) Life has theme & $(.43)$ \\
Q3) Future goals & $(.43)$ \\
Q21) Others help mood & $(.41)$ \\
& Self Function \\
Q13) Self is the same & $(.90)$ \\
Q14) How self changes & $(.64)$ \\
Q16) Values changed & $(.60)$ \\
Q17) Understand self & $(.49)$ \\
Nurturing Relationships & Social Function \\
Q22) Others feel better & $(.49)$ \\
Q28) Help others & $(.68)$ \\
Q25) Strong friendship & $(.62)$ \\
Developing Relationships & $(.59)$ \\
Q26) Learn other’s life & \\
Q27) Learn new person & \\
Q24) Closer relation & \\
\hline
\end{tabular}

"When something unexpected happens to me and I want to fit it into my view of my life”. Item 6 (.66) for the directive function suggests uncertainty about a relation between self and a choice to make in life: "When I need to make a life choice and I am uncertain which path to take". For both items, there is uncertainty about a relationship between self and an event or an experience; yet, for these two items the target of understanding could be considered the event, that is, the life choice or the unexpected event.

Self function. Item $13(.90)$ for the self function suggests uncertainty about who one is at present relative to a previous time, hence a relation between present self and past self: "When I am concerned about whether I am still the same type of person that I was earlier”. Item 13 seems to measure self-continuity. Item 14 (.64) on the other hand seems to measure self-change; thus, unlike item 13 which suggests uncertainty about whether one is the same, item 14 suggests uncertainty about how one has changed: "When I want to understand how I have changed from who I was before”. In short, item 13 focuses on how one is the same and item 14 focuses on how one is different. In both cases, however, there is uncertainty about a past-present self relationship and the target of understanding is the self.

Social function. Item 22 (.68) of the social function indicates a relation between the self and others: "When I want to make someone else feel better by talking to them about my similar past experiences". Likewise, item 26 (.66) of the social function indicates a self-other relation: "When I hope to learn more about that other person's life". The TALE suggests these two items reflect nurturing and developing relationships, respectively; however, at a more basic level these items may reflect meaning making through interpersonal relationships, and uncertainty reduction allows people to have predictability and control in their social structures. For both of these items the target of understanding is not the self but the other or someone else.

\section{Reinterpretation of the TALE}

Autobiographical memory is a recollection of personal experiences and is, therefore, inherently self-focused, or selfreferring (Brewer, 1986). Thus, the central target of understanding or meaning making is the "I" or the self; the self, however, may be understood in the context of events and others: events and others, then, also could be considered targets of meaning making. Uncertainty reduction in these targets, and the embedded relations, is a way to affirm a coherent and meaningful relational framework (see Figure 1). Accordingly, it is proposed that the TALE could be reinterpreted as uncertainty reduction about self, others, and events (RTALE).

\section{Uncertainty about Self (US)}

The reinterpretation of the TALE assumes that AM is self-focused; thus, it is suggested that a primary function of AM is meaning making and uncertainty reduction about the self. Bluck et al. (2005) showed that the TALE self function correlated .60 with the Reminiscence Functions Scale (RFS; Webster, 1993) subscale identity and .49 with the problem solving scale. Indeed, the two highest loading items from the TALE self function, items 13 and 14 , suggest that one is attempting to make sense of who one is and how one has changed over time, that is, sense making or problem solving about self. Considering that $\mathrm{AM}$ is principally about self and creating a coherent life story, it is suggested that, of the four proposed functions, the uncertainty about self function (US) will be the most influential variable, that is, account for the greatest amount of variance.

An aspect of personal identity that has not been addressed by the TALE is self-esteem, although self-esteem or similar such language (embarrassment, self-worth) is used or intimated in the majority of personal event memories provided by Pillemer (2001). Self-esteem is defined as how much value people place on themselves; that is, their self worth (Baumeister et al., 2003: p. 2). People use others and their experiences to develop a sense of who they are; moreover, people will integrate their experiences such that they verify their self-concepts (Swann, 1987). Thus, regardless of whether the self-conception is positive or negative, people will gather information and evidence to support or confirm their beliefs about who they are, thereby reducing the uncertainty about themselves and what to expect from the world. Indeed, people will respond to uncertainties in their 
identities by becoming more zealous in their attitudes and exhibiting greater certainty in their self-concepts (cf. Koole et al., 2006: p. 214). For example, even people with low self-esteem will avoid positive feedback because it is a threat to their self-concept; those with high self-esteem, however, will welcome positive feedback and react strongly against unfavorable feedback; thus, both groups act in a way that confirms and stabilizes their self-concept (Baumeister, Smart, \& Boden, 1996; Swann \& Hill, 1982). In sum, since self-esteem may be considered a central aspect of one's identity, and personal identity is a major existential concern, then it is logical to consider selfesteem as part of the self function.

\section{Uncertainty about Others (UO)}

The TALE also has a social function that will be retained but reinterpreted as an "uncertainty about other" function. As suggested above, the target of understanding for this function is the "other" not the self; yet, others are understood in the context of self. When one person seeks to learn about another, to make another feel better, or just be more connected to others, one seeks to understand and stabilize the social structure, which in turn fosters personal control and predictability about self-other relations.

\section{Uncertainty about Events (UE)}

Embedded within the directive function of the TALE is a recurrent theme of "something unexpected happens", "uncertainty about a life path", or a "life choice needs to be made". Indeed, the TALE items with the highest loadings on the directive function are those that suggest integrating the unexpected or uncertainty about a life choice, items 11 and 6, respectively. It is suggested that a separate TALE function is one of meaning making about an "event", or reducing uncertainty about an event. For example, someone receives an unexpected and very lucrative job offer; or, one is confronted with a very costly automobile or house repair. In all these cases uncertainty has been introduced via an unexpected event, and one is confronted with how to deal with the uncertainty created by the event. For this function, the target of uncertainty is the event, as opposed to the self (as in the uncertainty about self function), although the event occurs and imposes meaning relative to someone.

\section{Mortality Salience}

One event that is quite salient and widely studied in XXP is the existential concern of death or mortality salience (Koole et al., 2006). Death embodies uncertainty; yet, it is one of the few things in life that is certain; thus death is a unique event that we all will face. Webster's (1993) RFS subscale death preparation suggests that people will reminisce when their own mortality becomes salient. It is suggested that this process "contributes to a sense of closure and calmness (because it helps me see that I have lived a full life and can therefore accept death more calmly)” (Webster, 1993: p. 259). Thus death preparation is a way to reduce uncertainty about that which is inevitable.

The elderly score significantly higher on death preparation than young adults (Webster, 1998; Webster \& McCall, 1999). This stands to reason: as one gets older death becomes more salient; as we age the people close to use are more likely to die, as are we. Yet, it could be argued that from an early age we are being prepared for death: this preparation may be considered less strident, less direct, and more distal to our own sense of mortality. Recently, for instance, the US has experienced 9/11 and Hurricane Katrina; more recently there was the Chinese earthquake of 2008; also in 2008 India experienced the Mumbai terrorist attack; more recently yet was the 2011 Japanese tsunami. We also here about the deaths of famous celebrities: Princess Diane, and John F. Kennedy, Jr. And then we know of those who die in car accidents or are stricken with life threatening diseases, like cancer. Thus people will often think about these events as they occur; yet, many of these death events are often distal to one's own mortality; nonetheless this mortality salience, however distal, may serve a preparatory function. As conceptualized herein, it is suggested the mortality salience will be a separate AM function.

\section{Summary and Propositions}

One goal of this study is to replicate the TALE. Another goal of this study is to better understand how the functions of AM interact and support one another. Existential psychology provides for a meaning making framework, whereby meaning making is realized through relations; central to meaning making is uncertainty reduction. Thus, it is suggested that the AM functions interact and support one another through relational frameworks such that a consistent and coherent life story can be created and maintained. As such, the following is proposed:

- The AM functions are connected by relational links, that is, self-self; self-other; self-event; and other-event.

- Meaning making is created through these relational links, for example, a stimulus (event)-self relation; thus meaning making is an inextricable part of all AM functions.

- Meaning making develops in response to uncertainty reduction; thus uncertainty reduction is an inextricable part of all AM functions.

- Accordingly, the TALE will be reinterpreted as 4 uncertainty functions: uncertainty reduction about self; uncertainty reduction about others; uncertainty reduction about events; and mortality salience; embedded within these functions are the relational links discussed herein. Self-esteem will be part of the self function. In sum, it is proposed that the RTALE will have 4 separate functions, and the uncertainty about self function will provide the most explanatory variance.

- Also, it is expected that the TALE directive function will be highly correlated with the RTALE UE subscale; the TALE self function will be highly correlated with the RTALE US subscale; the TALE social function will be highly correlated with the RTALE UO subscale; and the TALE directive function will be significantly associated with all the RTALE subscales.

\section{Method}

\section{Participants}

Participants were 185 undergraduate students at a mid-size, northeastern state university. Six participants provided incomplete data and were dropped from the analysis. The final sample consisted of 179 participants, 124 women and 55 men, age range 18 to 47 years $\left(M_{\text {age }}=19.83, S D=4.03\right)$. Participants were given credit for their participation. 


\section{O. J. OLIVARES}

\section{Procedure and Measures}

All participants completed two questionnaires: The TALE (Bluck et al., 2005) and the reinterpreted TALE (RTALE). The questionnaires were counterbalanced such that approximately half of the participants completed the TALE first and half of the participants completed the RTALE first.

The TALE consists of 4 factors (3 functions) and 24 items: 14 items on the directive function; 4 items on the self function; and 3 items each on the nurturing relationships and developing relationship, that is, 6 items on the social function (see Table 1; from Bluck et al. (2005); Table 2, p. 101).

The RTALE was designed not to supplant the TALE but as a reinterpretation of the TALE; moreover, the TALE was the primary source for the development of the RTALE; accordingly, the largest factor loadings from each of the TALE functions were used as seed items for the RTALE. For example, items 6 and 11 of the directive function were about unexpected events and uncertainty about life choices; thus, these two items became part of the uncertainty about events (UE) function. Items 13 and 14 of the self function were the highest loading items on the TALE self subscale and, therefore, became part of the uncertainty about self (US) function. Likewise, items 22 and 26 of the social function were the highest loading items on the social function and became part of the uncertainty about others (UO) function. RTALE items from the TALE with the highest loadings are provided with an asterisk (see Table 2 for the RTALE questionnaire).

Table 2.

RTALE Items for the uncertainty about self (and self-esteem), events, others, and mortality salience functions of AM.

\begin{tabular}{ll}
\hline Item & \multicolumn{1}{c}{ Uncertainty about Self Function } \\
\hline 2) & I am concerned about whether I am still the same type of person that I was earlier. \\
9) & I compare myself to what I was like before. \\
16) & I am trying to understand how I have changed over time. \\
20) & I am trying to figure out who I am. \\
25) & I am trying to get a sense of how I fit into the world. \\
26) & I am trying to understand who I am now.
\end{tabular}

26) I am trying to understand who I am now.

\section{Self Esteem}

3) I question my sense of worth, or self worth.

6) I was ashamed about something that I had done.

13) I was embarrassed about something that happened to me.

22) I am not satisfied with myself.

24) My self-esteem was threatened.

15) I questioned my ability to do something.

Uncertainty about Events Function

1) I am confronted with different choices in my life and I am not sure what to do."

5) Unexpected events occur in my life and I am trying to figure out what to do.*

8) There is uncertainty in my life and I am trying to figure out what I should do.

17) I am trying to make sense of my life experiences.

21) I am trying to understand the meaningfulness of life events.

\section{Uncertainty about Others Function}

4) I want to help someone else by telling them about my own experiences.

10) I want to better understand someone else's life.

19) I want to share my experiences with someone else.

23) I want to know what that other person would do if "they were in my shoes".

27) I want to learn from another person.

12) I want to feel more connected to someone else.

Mortality Salience Function

7) A tragic event kills lots of people (e.g., 9/11, Katrina).

11) Someone I know dies.

14) Someone I know is critically injured in an accident.

18) Someone I know experiences a life-threatening event (e.g., cancer).

28) I seek to understand my own mortality, that is, I will die at some time.

*Items from the TALE with highest loadings. 
The remaining items and scales were developed using the XXP literature (Koole et al., 2006), the AM literature (e.g., Pillemer, 2001), and the self-esteem literature (Baumeister et al., 2003; Rosenberg, 1965). In the XXP, for instance, the basic concern of identity asks the questions: "Who am I", and "How do I fit in this world” (Koole et al., 2006: p. 213). These questions became part of the US subscale. The existential concern of isolation focuses on connecting with others and sharing subjective experiences, and these basic notions became part of the UO subscale. The self-esteem scale was an amalgam of Rosenberg's self esteem scale and case studies provided by Pillemer (2001).

The mortality salience (MS) subscale was constructed in such a way that mortality salience was induced by external events. The intention here was to excise the "self" from the death event; in other words, the items were not designed to elicit one's thoughts about his or her death and preparing for this inevitable event; rather death is conceptualized as an "otherevent” occurrence. In contrast, Webster's (1993) death preparation subscale is self-focused: “...because I feel less fearful of death after I finish reminiscing” and “...because it helps me see that I've lived a full life and can therefore accept death more calmly". However, one self-focused item (item 28) was added as "a check" or to validate this distinction. In sum, the RTALE consists of 4 functions and 28 items: 12 US items, including 6 self-esteem items, 5 UE items, 6 UO items, and 5 MS items.

From Bluck et al. (2003: p. 97), the following procedure was used:

To establish individuals' overall tendency for thinking about and talking about the past, participants first provide responses to two introductory questions: "How often do you think back over your life?" and "How often do you talk to others about what's happened in your life so far?" To these items, and throughout the questionnaire, responses were made on a 6-point Likert-type scale, ranging from never (1) to very frequently (6).

After these two questions the participants were provided with the 24 item TALE and 28 item RTALE. As previously mentioned, the two measures were counterbalanced. Per Bluck et al., the stem statement for each question on both measures was: "I think back over or talk about my life or certain periods of my life..." The items for each measure were randomly ordered. Also, participants were asked to provide information regarding their gender, age, and class rank.

\section{Results}

The results of this study are considered in three parts: 1) a replication of the TALE using an exploratory factor analysis (EFA), as in Bluck et al. (2005); 2) an EFA of the RTALE; 3) an exploration of the relationship between the TALE and the RTALE.

\section{Replication of the TALE}

Order effect. A one-way multivariate analysis of variance (MANOVA) with seven dependent variables was computed in order to determine the potential effect of order on the way participants responded to the items that represented the various factors for each measure. The between variable was the order in which the two measures were taken. The dependent measures were the proposed 3 factors represented by the TALE and the 4 factors represented by the RTALE. Using Wilk's criterion, the combined dependent variables were not significantly affected by order, $F(7,171)=1.64, p=.12$; thus, the order in which the participants received the measures did not affect the way they responded to the two instruments.

\section{Replication of the TALE: Exploratory Factor Analysis}

Considering that this is the first replication of the TALE, EFA was conducted to determine whether Bluck et al.'s three factors would emerge. As such, the methods used in this analysis follow those of Bluck et al. For example, factors were extracted using a common factors model (principal axis) with a Promax rotation, meaningful factor loadings were identified as .40 or higher, and the pattern matrices are provided.

Bluck et al. found four factors, but suggested that these findings should be interpreted with caution: As part of this 4 factor solution the social factor was decomposed into two factors. Thus, in this study the initial analysis sought to extract 4 factors: This resulted in a fourth factor with only 2 items, with one item loading at .41: these two items were directive items. A more parsimonious three factor solution was sought and found to account for $48.64 \%$ of the variance, very similar to the $49.99 \%$ found by Bluck et al.'s 4 factor solution. Two items, item 6 ("When I need to make a life choice and I am uncertain which path to take") and item 7 ("When I am search for a solution to a problem") did not load above .40 on any factor. Interestingly, item 6 was the second highest loading item on the TALE directive function.

\section{Interpretation of the Replicated TALE Factors}

Table 3 provides a summary of the items that represent the factors, the item loadings, the amount of variance explained by each factor, and Cronbach's alpha for each factor. The first factor, which consisted of 11 items and accounted for 31\% of variance, was a combination of self and directive items: 7 of these items were directive items and 4 were self items. Bluck et al.'s first factor was called a directive function and consisted of 14 items, 8 which were directives items, 5 which were originally self items, and 1 which was originally a social item. Thus, one may be inclined to interpret this factor as a directive function; however, this factor could be interpreted as a self function for three reasons: 1) 3 of the 5 highest loading items are self items, including the 1st and 3rd items; and 2) the directive items seem to be self-focused, that is, these items are concerned with making sense of one's life, thereby supporting the self function; and 3) there are no other factors that contain self-items; in contrast, the third factor is represented by 4 directive items. The highest loading (.78) item on the first factor of the replicated TALE was also the highest loading item on the TALE self function. This item is concerned with self continuity and whether one is the same as they were at an earlier time. The 3rd and 5th highest loading items on factor one are concerned with understanding self and how one may have changed. The rest of the items within this factor, although 7 are directive items, are concerned with making sense of one's life, that is, seeking to understand causal events, learning from an event, and trying to create a coherent life picture. In sum, the first factor appears to be self-focused, is concerned with making sense of one's place in the world, and with the basic existential theme of self-identity. 


\section{O. J. OLIVARES}

Table 3.

Replicated TALE items with factor loadings: 3-factor EFA with Promax Rotation.

\begin{tabular}{|c|c|}
\hline Item & Self Function \\
\hline Q13) Self is the same & $(.78)(\mathrm{s})^{*}$ \\
\hline Q1) Learn lesson & (.72) (d) \\
\hline Q14) How self changes & $(.71)(\mathrm{s})^{*}$ \\
\hline Q20) What caused this & (.69) (d) \\
\hline Q17) Understand self & (.68) (s) \\
\hline Q15) Life has theme & (.61) (d) \\
\hline Q5) Learn from error & (.59) (d) \\
\hline Q16) Values changed & $(.54)(\mathrm{s})$ \\
\hline Q10) Know problem & (.54) (d) \\
\hline Q11) Integrate unexpected & $(.50)(d)^{*}$ \\
\hline Q18) Reinterpret past event & (.47) (d) \\
\hline Variance explained & $30.77 \%$ \\
\hline Cronbach’s alpha & .87 \\
\hline \multicolumn{2}{|c|}{ Social Function } \\
\hline Q22) Others feel better & $(.84)(\mathrm{so})^{*}$ \\
\hline Q28) Help others & $(.74)(\text { so) })^{*}$ \\
\hline Q26) Learn other's life & $(.71)(\mathrm{so})^{*}$ \\
\hline Q24) Closer relation & (.70) (so) \\
\hline Q27) Learn new person & (.70) (so) \\
\hline Q21) Others help mood & (.47) (d) \\
\hline Q25) Strong friendship & (.46) (so) \\
\hline Variance explained & $11.54 \%$ \\
\hline Cronbach’s alpha & .84 \\
\hline \multicolumn{2}{|c|}{ Inspirational Function } \\
\hline Q19) Feel better & (.82) (d) \\
\hline Q4) Face challenge & (.69) (d) \\
\hline Q3) Future goals & (.47) (d) \\
\hline Q9) Recall advice & (.44) (d) \\
\hline Variance explained & $6.33 \%$ \\
\hline Cronbach’s alpha & .68 \\
\hline \multicolumn{2}{|c|}{ Loadings less than .40 on all factors } \\
\hline \multicolumn{2}{|l|}{ Q7) Problem solving (d) } \\
\hline Q6) Life choice (d) ${ }^{*}$ & \\
\hline
\end{tabular}

Note: "Highest loading items from the TALE: $(\mathrm{s})=$ self item from the original TALE; (so) = social item from the original TALE; $(\mathrm{d})=$ directive item from the original TALE .

The second factor consisted of 7 items, accounted for $12 \%$ of the variance, and was easily interpreted as the social function. Six of the seven items were social items, with factors loadings that mirrored Bluck et al.'s findings. A seventh item, item 21, which Bluck et al. originally developed as a social item, but then found it loaded on the directive function, also loaded on this factor.

The third factor explained $6 \%$ of the variance and consisted of 4 directive items. These items, however, present a theme that may be interpreted as "inspirational". The two highest loading items, item 19 (.82) and item 4 (.69), suggest that one is searching for hope and confidence: "When I am down and I want to make myself feel better" and "When I am facing a challenge and I want to give myself confidence". The other two items indicate that one is reaching out for advice and thinking about future goals. Thus, unlike the TALE directive function that suggests a reasoning or problem solving function, this factor seems to reflect a more affective function. Interestingly, item 7, which is concerned with problem solving, did not load on factor 3, or any other factor. However, at this point, any firm inferences about how to interpret this factor are made with caution.

In sum, the replication of the TALE yielded 3 factors, like the original TALE; however, only the second factor lends itself to a clear, unambiguous interpretation: a social function. Factor 1 , which consisted of 11 items and explained the greatest amount of variance, was a combination of self and directive items, as found by Bluck et al.; however, for this sample, it is suggested that the first factor represents a self function; The interpretation of the third factor is more difficult yet, given its relatively low internal consistency and the nature of the items; perhaps it is an "inspirational/hope" factor, or some other affective factor, like self-efficacy. Given the data, it is not quite clear what this factor represents; however, considering these limitations, it will be labeled an "inspirational" factor.

Considering the uniqueness of the third factor, the reliability of this factor, and that the fact that the four items that represent this function loaded on the directive function in the Bluck et al. sample, a two-factor solution was computed. A two-factor solution poorly represented the data. The four items in question did not load on any factor and only $42 \%$ of the variance was explained. Thus, for this sample the three-factor solution seems to best represent the data.

Table 4 provides the correlation matrix for the replicated TALE. This pattern matrix is very similar to that found by Bluck et al. The correlations are modest, indicating that the AM functions are related but unique. As in Bluck et al., the self and directive (inspirational) functions show the highest association.

\section{Exploratory Factor Analysis of the RTALE}

It was suggested that the RTALE would have 4 factors; thus, a 4-factor solution was sought. The EFA, using the same criteria as above, suggested 4 factors. A four-factor solution was found that accounted for $55 \%$ of the variance. The 4 factors were easy to interpret and all factors had respectable reliabilities, ranging from .92 to .80 (see Table 5). Of the 28 items, four items did not load above .40 on any factor: items 13, 22, 27, and 28. Items 13 and 22 are self-esteem items; item 27 is a social or other item; and item 28 is a mortality salience item. It was expected that item 28 would not load on any item.

Table 4.

Factor correlation matrix for the replicated TALE.

\begin{tabular}{lccc}
\hline & \multicolumn{3}{c}{ Factor } \\
\hline Factor & 1 & 2 & 3 \\
1. Self & 1.00 & & \\
2. Social & .36 & 1.00 & \\
3. Inspirational & .45 & .37 & 1.00 \\
\hline
\end{tabular}

Note: All associations are significant at $\mathrm{p}<.001$. 


\section{O. J. OLIVARES}

Table 5.

Factor pattern matrix with factor loadings for the RTALE questionnaire: 4-factor EFA with promax rotation.

\begin{tabular}{lc}
\hline \multicolumn{1}{c}{ Item } & Uncertainty about Self Function \\
\hline 26) I am trying to understand who I am. (us) & .94 \\
16) I am trying to understand how I have changed over time. ${ }^{*}$ (us) & .80 \\
2) I am concerned about whether I am still the same type of person that I was earlier. ${ }^{*}$ (us) & .76 \\
25) I am trying to get a sense of how I fit into the world. (us) & .76 \\
9) I compare myself to what I was like before. (us) & .74 \\
17) I am trying to make sense of my life experiences. (ue) & .69 \\
20) I am trying to figure out who I am. (us) & .67 \\
22) I am not satisfied with myself. (se) & .65 \\
3) I question my sense of worth, or self worth. (se) & .61 \\
6) I was ashamed about something that I had done. (se) & .56 \\
21) I am trying to understand the meaningfulness of life events. (ue) & .53 \\
24) My self-esteem was threatened. (se) & .50 \\
Variance explained & $32.33 \%$ \\
Cronbach's alpha & .92
\end{tabular}

\section{Uncertainty about Others Function}

10) I want to better understand someone else's life. (uo) $\quad .76$

12) I want to feel more connected to someone else. (uo) $\quad .74$

19) I want to share my experiences with someone else. (uo) $\quad .74$

4) I want to help someone else by telling them about my own experiences." (uo) $\quad$.62

27) I want to learn from another person. (uo) $\quad .59$

Variance explained $11.55 \%$

$\begin{array}{ll}\text { Cronbach’s alpha } & .81\end{array}$

\section{Mortality Salience Function}

18) Someone I know experiences a life-threatening event (e.g., cancer). (ms) $\quad .94$

14) Someone I know is critically injured in an accident. (ms) $\quad .88$

11) Someone I know dies. (ms) $\quad .70$

7) A tragic event kills lots of people (e.g., 9/11, Katrina). (ms) $\quad .41$

Variance explained $\quad 6.87 \%$

$\begin{array}{ll}\text { Cronbach's alpha } & .82\end{array}$

\section{Uncertainty about Events Function}

8) There is uncertainty in my life and I am trying to figure out what I should do. (ue) $\quad .90$

5) Unexpected events occur in my life and I am trying to figure out what to do. ${ }^{*}$ (ue) $\quad .73$

1) I am confronted with different choices in my life and I am not sure what to do." (ue) $\quad .52$

$\begin{array}{ll}\text { Variance explained } & 4.72 \%\end{array}$

$\begin{array}{ll}\text { Cronbach’s alpha } & .80\end{array}$

Loading less than .40 on all factors

13) I was embarrassed about something that happened to me. (se)

15) I questioned my ability to do something. (se)

23) I want to know what that other person would do if "they were in my shoes".

(uo)

28) I seek to understand my own mortality, that is, I will die at some time. (ms)

*Highest loading items from the TALE; (us) = uncertainty about self; (ue) = uncertainty about events; (uo) = uncertainty about others; (ms) = mortality salience. 


\section{O. J. OLIVARES}

The 4 factors identified in this analysis were as predicted. Also as predicted was factor 1 as the most influential variable; factor 1 explained 32\% of the variance. It could be argued that the US function had a disproportionate number of items and this is why this factor accounted for considerable more variance than the other factors. Factor 1 had 12 items compared to ap- proximately 6 for the other functions. Six of the 12 items were self-esteem items. In order to test for the influence of the US function, without a disproportionate number of items, the EFA was recomputed without the 6 self-esteem items. Table 6 provides the factor pattern matrix and associated statistics. The results indicate a parsimonious 4 -factor solution that explains

Table 6.

Factor pattern matrix with factor loadings for the RTALE questionnaire: 4-factor EFA with promax rotation, less the self-esteem items.

\begin{tabular}{|c|c|}
\hline Item & Uncertainty about Self Function \\
\hline 26) I am trying to understand who I am. (us) & .93 \\
\hline 16) I am trying to understand how I have changed over time. " (us) & .84 \\
\hline 2) I am concerned about whether I am still the same type of person that I was earlier.* (us) & .73 \\
\hline 9) I compare myself to what I was like before. (us) & .71 \\
\hline 25) I am trying to get a sense of how I fit into the world. (us) & .71 \\
\hline 17) I am trying to make sense of my life experiences. (ue) & .70 \\
\hline 20) I am trying to figure out who I am. (us) & .66 \\
\hline 21) I am trying to understand the meaningfulness of life events. (ue) & .54 \\
\hline Variance explained & $32.95 \%$ \\
\hline Cronbach’s alpha & .90 \\
\hline \multicolumn{2}{|l|}{ Uncertainty about Others Function } \\
\hline 19) I want to share my experiences with someone else. (uo) & .78 \\
\hline 10) I want to better understand someone else's life. (uo) & .76 \\
\hline 12) I want to feel more connected to someone else. (uo) & .74 \\
\hline 4) I want to help someone else by telling them about my own experiences. ${ }^{*}$ (uo) & .64 \\
\hline 27) I want to learn from another person. ${ }^{*}$ (uo) & .59 \\
\hline Variance explained & $13.17 \%$ \\
\hline Cronbach’s alpha & .81 \\
\hline \multicolumn{2}{|l|}{ Mortality Salience Function } \\
\hline 18) Someone I know experiences a life-threatening event (e.g., cancer). (ms) & .94 \\
\hline 14) Someone I know is critically injured in an accident. (ms) & .88 \\
\hline 11) Someone I know dies. (ms) & .69 \\
\hline 7) A tragic event kills lots of people (e.g., 9/11, Katrina). (ms) & .42 \\
\hline Variance explained & $8.46 \%$ \\
\hline Cronbach's alpha & .82 \\
\hline \multicolumn{2}{|l|}{ Uncertainty about Events Function } \\
\hline 8) There is uncertainty in my life and I am trying to figure out what I should do. (ue) & .90 \\
\hline 5) Unexpected events occur in my life and I am trying to figure out what to do. ${ }^{*}$ (ue) & .72 \\
\hline 1) I am confronted with different choices in my life and I am not sure what to do." (ue) & .57 \\
\hline Variance explained & $5.83 \%$ \\
\hline Cronbach’s alpha & .80 \\
\hline \multicolumn{2}{|l|}{ Loading less than .40 on all factors } \\
\hline 23) I want to know what that other person would do if "they were in my shoes". (uo) & \\
\hline 28) I seek to understand my own mortality, that is, I will die at some time. (ms) & \\
\hline
\end{tabular}

"Highest loading items from the TALE; (us) = uncertainty about self; (ue) = uncertainty about events; (uo) = uncertainty about others; (ms) = mortality salience. 
$60.41 \%$ of the variance with 20 items. Factor 1 explained 33\% of the variance; thus, factor 1 explained $1 \%$ more variance with 6 fewer items.

These findings suggest that there is considerable redundancy provided by the self-esteem scale, that is, collinearity between self-esteem and the other scales or functions, namely the US function: the correlation between self-esteem and the US function was quite high, $r=.70, \mathrm{p}<.001$. Thus, self-esteem does not seem to add any additional variance; rather, it seems to consume variance that would be otherwise accounted for by the other functions. One test for redundancy is to show that the zero-order correlations among the functions are greater than the partial correlations: the correlations controlling for self-esteem (Cohen \& Cohen, 1983). All the partial correlations were considerably lower than the zero-order correlations, for example, the zero-order correlation between US and UE functions was .49; the partial correlation between these two functions was .28 , a $43 \%$ drop in strength of association. Considering these findings, all subsequent computations and analyses will use the 20-item RTALE found in Table 6.

\section{Interpretation of the RTALE Factors}

Factor 1. The factor explained $33 \%$ of the variance and is represented by 8 items. The item loadings on this factor seem to reflect the uncertainty about self function. The highest loading on this factor is .93: "I am trying to understand who I am". The item squarely focuses on uncertainty about self, and the uncertainty associated with understanding oneself. The next four highest loading items, which range from .84 to .71, are also self-focused items, and are associated with the theme of understanding how I fit into the world, how I have changed over time, and whether I am the same person I used to be: two of these four items were the highest loading items from the TALE self function. Two of the uncertainty about events items also loaded on this factor: these two items focused on making sense of life experiences and the meaningfulness of life events; although these items are about experiences and events, the data suggest that participants' responses are self-focused vis-à-vis an experience; that is, the target of understanding is the self, as opposed to the event or experiences. In sum, this factor may be interpreted as an uncertainty about self function.

Factor 2. This factor explained $13 \%$ of the variance and is represented by 5 items. The data suggests that factor 2 represents a social function; however, here it is interpreted as uncertainty about others. The three highest loading items, which range from .78 to .74 , focus on connecting with, and better understanding, someone else. It is suggested that this factor focuses on reducing uncertainty in social structures, thereby creating meaningful interpersonal relationships.

Factor 3. This factor explained $8 \%$ of the variance and is represented by 4 items. The data suggest that Factor 3 represents the mortality salience function. The highest loading item on this factor, .94, is: "Someone I know experiences a life threatening event". This item, and other items within this factor, suggests a mortality salience function that is not self-focused per se, like Webster's (1993) RFS subscale death preparation, but rather a death preparatory function that is realized through other-event relationships. Item 28 ("I seek to understand my own mortality, that is, I will die at some time"), was written to check the distinction between a self-focused and other-event-focused death preparatory function. Indeed, this item did not load above .40 on any factor: the highest loading was .27 on factor 1 , the uncertainty about self function.

Factor 4. This factor is represented by 3 items, explained 6\% of the variance. The data suggest that this factor reliably represents an uncertainty about events function. All the items reflect an uncertainty about what to do with events and experiences that one confronts. Unlike factor 1, where the target of understanding is the self, factor 4's target of understanding is an event or an experience. In short, it is suggested this factor represents a meaning making function with respect to uncertain events and occurrences within one's life.

The factor correlation matrix for the RTALE is reported in Table 7. Interestingly, the UE factor, with only 3 items, showed the highest correlations across the other factors. All other correlations are modest. However, the pattern of associations found in Table 7 is consistent with Pillemer (2003) who suggests that meaning making is a fundamental function of AM; that is, meaning making serves all AM functions. These findings are also consistent with the arguments presented herein that suggests meaning making is found in relations, and how relations are integrated in some causally coherent fashion (Heine et al., 2006); moreover, the item content of the factors suggests that central to meaning making is understanding and reducing uncertainty about oneself, events, and social structures; thus, these data suggest that meaning making and uncertainty reduction may indeed be inextricable parts of all AM functions.

\section{The Replicated TALE and the RTALE: An Inter-Measure Analysis}

Inter-factor analysis. The inter-measure analysis will provide some convergent validity evidence regarding the 3-factor solution of the replicated TALE and the 4-factor solution of the RTALE. Considering the uncertainty associated with the 3rd factor of the replicated TALE, caution is in order when examining the evidence presented below.

As predicted, the TALE self function was strongly associated with the RTALE US function, $r=.77, \mathrm{p}<.001$ (see Table 8). Also, the TALE social function was strongly associated with the RTALE UO function, $r=.81, \mathrm{p}<.001$. The third factor of the TALE was most highly associated with RTALE UE function, $r=.51, \mathrm{p}<.001$ : this provides some evidence that the 3rd factor of the replicated TALE represents an AM function related to uncertainty about events or experiences in one's life, for example, feeling down or facing a challenge (uncertainty) and searching for a way to feel better or more confident. It was also predicted that the "directive" function of the TALE (third factor of the replicated TALE) would be significantly associated with all the RTALE functions; although this is true, the

Table 7.

Factor correlation matrix for the reinterpreted TALE (RTALE).

\begin{tabular}{lcccc}
\hline & \multicolumn{5}{c}{ Factor } \\
\hline Factor & 1 & 2 & 3 & 4 \\
1. Uncertainty self & 1.00 & & & \\
2. Uncertainty others & .30 & 1.00 & & \\
3. Mortality salience & .25 & .33 & 1.00 & \\
4. Uncertainty events & .49 & .40 & .38 & 1.00 \\
\hline
\end{tabular}

Note: All associations are significant at $\mathrm{p}<.001$. 
Table 8.

Factor correlation matrix for the tale and reinterpreted TALE (RTALE).

\begin{tabular}{lccc}
\hline & \multicolumn{3}{c}{ TALE } \\
\hline RTALE & Self & Social & Inspirational \\
1. Uncertainty self & .77 & .30 & .32 \\
2. Uncertainty others & .33 & .81 & .35 \\
3. Mortality salience & .31 & .35 & .37 \\
4. Uncertainty events & .58 & .40 & .51 \\
\hline
\end{tabular}

Note: All associations are significant at $\mathrm{p}<.001$.

TALE self function showed a similar pattern of associations across the RTALE functions; hence, this pattern of associations, along with the individual item loadings on the self function of the TALE, suggest that the first factor of the replicated TALE may be a self function, rather than a directive function. In sum, these data provide some convergent validity evidence for the 3 -factor solution of the replicated TALE and the 4-factor solution of the RTALE.

Intra-item analysis: TALE-replicated TALE. The greater the item loading, the more the item is a pure measure of the factor (Tabachnick \& Fidell, 2007: p. 649); thus, it is expected that the highest loading items on the TALE would show similar loadings in the replicated TALE. Indeed, this was the case for the items representing the self and social factors (see Table 3). Items 13 and 14 from the TALE were the highest loading items on the self function: on the replicated TALE these two items represented the 1st and 3rd highest loading items on the first factor, which was labeled a self factor. Items 22 and 26 were the highest loading items on the social function of the TALE: These items loaded 1st and 3rd on the replicated social factor. The only deviation from this pattern was found with the directive function. The highest loading items on the TALE directive function were items 11 and 6: on the replicated TALE item 11 loaded on the self function, .50; item 6 did not load on any factor. In sum, this item-analysis provides support for the self and social factors, but not the directive factor.

Intra-item analysis: TALE-RTALE. It was suggested that the highest loading items on each of the TALE functions were imbued with uncertainty about self, others, or events; as such these items were used as seed items in the development of the RTALE; it was expected, therefore, that these items would load on the corresponding uncertainty functions. For example, the highest loading items on the TALE self function were items 13 (.90) and 14 (.64). These two items were the 2nd and 3rd highest loading items on the RTALE uncertainty about self function: loadings were .84 and .73, respectively (see Table 6). Likewise items 22 and 26 were the highest loading items from the TALE social function. Two very similar items were written for the RTALE uncertainty about others function, items 4 and 27, both which loaded on the uncertainty about others function: loadings were .64 and .59 , respectively. Similarly, the two highest loading items on the TALE directive function were items 11 (.68) and 6 (.66), and these two items loaded on the RTALE uncertainty about events function, .73 and .57 , respectively.

The highest loading items on the US, UO, UE, and MS functions reflect uncertainty about relations, for example: "I am trying to understand who I am" (.93); "I want to better understand someone else's life" (.78); "There is uncertainty in my life and I am trying to figure out what I should do" (.90); and
“Someone I know experiences a life-threatening event” (.94). In sum, these analyses supports the contention that the RTALE functions reflect uncertainty about self, others, and events.

\section{Discussion}

\section{The Replicated TALE}

One goal of the present study was to replicate the empirical structure of the TALE: directive, self, and social functions. Using methods provided by Bluck et al., and a similar sample size, results suggest some support for the three functions captured by the TALE and consistently mentioned in the literature; however, excepting the social function, the item to function mapping was dissimilar and, therefore, the interpretation of 2 of the three factors was dissimilar. For instance, a self function that consisted only of self items was not found; rather, a self function was identified that consisted of 11 items: 4 self items and 7 directive items. Also, a broad directive function was not found; rather, a narrow function labeled inspirational, that consisted of 4 directive items, was identified.

As in Bluck et al. (2005), the present study found considerable overlap between the self and directive functions. For this sample, a separate self-function was not identified; rather, the self-function possessed directive items that seemed to reflect learning, reasoning, and meaning making about self. Thus, it seems that autobiographical reasoning may be an inextricable component of one's self-function: autobiographical reasoning may be used to make sense of one's experiences (McLean, 2005), and thereby aid in the construction of a coherent life story (e.g., Habermas \& Bluck, 2000; Wilson \& Roth, 2003).

A unique finding in this study was a third factor that consisted of four directive items that seemed to focus on serving an inspirational function (e.g., Pillemer, 1998). For example, the two most influential items on this factor spoke to making oneself feel better or giving oneself confidence. Descriptive data suggests that this function $(M=3.93, S D=.90)$ was endorsed as frequently as the self function $(M=3.92, S D=.87)$, and at about the same frequency as the Bluck et al. directive function $(M=3.86, S D=.79)$. Thus there may have been a need to access and isolate an aspect of the directive function that focuses specifically on satisfying more emotionally-based needs (e.g., Woike, Mcleod, \& Goggin, 2003). In short, it is possible that the directive function found in the replicated TALE may simply reflect the experiences and needs of the sample.

Thus far it has been suggested that autobiographical reasoning and meaning making are central needs or concerns of autobiographical memory. Another enduring need of autobiographical memory is the need for relationships. Humans are communal and the need for social contact is relatively invariant across peoples. The results of this study support this basic notion: The social function of the replicated TALE produced results almost identical to the original TALE; however, only 1 factor was found, not 2; thus, in the present study participants did not distinguish between the nurturing and developing relationships factors. The results suggest that the social function is quite stable and generalizable.

\section{The Reinterpreted TALE (RTALE)}

Another goal of the current research was to better understand how the functions of AM interact and support one another, that is, to better understand the psychological mechanisms that may 
underlie AM. Existential psychology was used to develop a relational framework that suggests meaning is found in relations, and meaning making develops in response to uncertainty reduction. Moreover, it was suggested that the TALE items were imbued with lexical content that conveys uncertainty reduction; hence the TALE was reinterpreted in the context of the relational framework conceptualized herein. A 28 item selfreport measure was developed to assess 4 hypothetical functions related to uncertainty reduction: uncertainty about self; uncertainty about events/experiences; uncertainty about others; and mortality salience. The results supported a 20 item measure that identified a 4 -factor structure that explained $60 \%$ of the variance.

The RTALE conceptualization also allowed for the inclusion of two additional functions: a mortality salience function and a self-esteem function. Mortality salience was conceptualized as a death preparatory function; however, unlike Weber (1993), it was considered an "other-event" phenomenon. Death, perhaps, is one of the few certainties in life that logically fits within a relational, uncertainty framework. Empirical evidence supported a death preparatory function that was not self-centered; indeed, the mortality salience function showed a pattern of associations such that it correlated most strongly with the uncertainty about events function and least strongly with the uncertainty about self function; also, the one item on the mortality salience scale that was self-focused did not load on any factor.

Self-esteem was included as part of the self function; however, a priori it was not known how the self esteem items would load. However, since self-esteem was considered as an integral part of one's self-identity, and instrumental in creating a consistent and coherent life story (e.g., Wilson \& Roth, 2003), then it seemed reasonable to include self-esteem as part of the self function. The results indicated that self-esteem was redundant with the self function, and that it did not add any explanatory value to the RTALE; in fact, when the self-esteem items were removed from the measure, the explanatory variance increased. These findings do not suggest that self-esteem is not a critical part of the self function; rather, it suggests that the self function, as measured by the RTALE, subsumed self-esteem.

\section{Study Limitations}

Bluck et al. (2005), in discussing their study's limitations noted that their "overall factor solution accounted for $50 \%$ of the variance" (p. 111). The current study found the TALE had an overall factor solution that accounted for approximately $50 \%$ of the variance. Thus, the same critique could be provided for this study. However, it was not the purpose of this study to refine the quality of the items of the TALE; rather, one purpose was to use the same measure and methods in order to replicate the findings. Considering this goal, the results are as encouraging.

On the other hand, The RTALE used a different theoretical framework for developing items, although the highest loading items from the RTALE were incorporated. Thus, one could argue that the RTALE capitalized on common method variance; however, the goal in developing the RTALE was not to supplant the TALE but to develop a quasi-new measure that captured the lexical content of the TALE and was guided by an existential and social-cognitive framework. In the final analysis, the RTALE consisted of 20 items and accounted for $60 \%$ of the variance; thus, the RTALE resulted in a sizeable improvement, relative to the TALE.
Another possible limitation of this study is the sample size. Although there are number of indicators that suggest an adequate sample size-for example, the Kaiser-Meyer-Olkin measure of sampling adequacy was .86 and .85 for the TALE and RTALE, respectively, there were only 3 or 4 distinct factors, and there were quite a few items with strong correlations (Tabachnik \& Fidell, 2007)—one may reasonable argue that the findings of the replicated TALE reflect sampling error. The sample in this study consisted of young undergraduates from a state university in New England; this is a very different sample from the Bluck et al. study, which consisted of young undergraduate students at Duke University.

\section{Directions for Future Research}

To echo Bluck et al., one obvious direction for future research would be to administer the TALE and RTALE to a larger and much more diverse sample. It would be interesting, for example, to merge the TALE data from the current study with the Bluck et al. data. This would still result in a relatively young sample, but socioeconomically and geographically the sample would be much more diverse; moreover, given that the sample size would double, the factor structure would be more stable.

In this study it was suggested that AM represents experiences with a certain degree of accuracy, as well as form meaning for the individual (Conway, 2003). People are more likely to remember experiences that pertain to goals that are consistent with their self-concept, for example, agentic (task-oriented) individuals tend to remember experiences related to mastery or achievement, whereas communal individuals to remember experiences about relationships (Woike, Mcleod, \& Goggin, 2003); thus, personality-based individual differences may influence the accessibility of AM. A personality trait related to agentic-types is conscientiousness. Conscientiousness has found to be a consistent, positive correlate of self-efficacy, or performance motivation (Judge \& Ilies, 2002), and self-efficacy has been found to be consistently related to achievement and goal completion (Locke \& Latham, 2002).

Recently, Rentfrow, Gosling, and Potter (2008) found regional variations in personality traits across the US, as measured by the Five Factor Model (FFM; i.e., Extraversion [E], Agreeableness [A], Conscientiousness [C], Neuroticism [N], and Openness [O]) (Goldberg, 1990). Massachusetts, the state represented by the students in this study, had one of the lowest C scores in the country ( $\operatorname{rank}=43 ; z=-0.75$ ); in general, state-level C was lowest in the Mid-Atlantic and New England states and highest in the Southwest, Midwest, and Southeast states. Interestingly, Massachusetts also had one of the lowest E scores (rank $=43 ; z=-0.81$ ). Thus it is possible that regional differences in experiences and personality traits may affect both how experiences are interpreted and how autobiographical memories are accessed and used (e.g., Woike et al., 2003). Future research should consider the potential relationships between regional differences in personality, demographics, and the use and structure of AM.

The fourth factor of the reinterpreted TALE was labeled inspirational; however, this factor could be labeled self-efficacy. The two highest loading items speak to making one's self feel better and finding confidence; the other two items speak to thinking about future goals and seeking advice because one does not know what to do. Thus, it is possible that the sample in this study had a "unique" need to isolate and use a self-efficacy 
or inspirational-like function. Perhaps this sample represents a group of students who have challenges and goals, but don't really know how to go about meeting the challenges or accomplishing the goals. Future research should consider self-efficacy as another potential AM function.

Finally, future research may want to empirically test the viability of the RTALE. The RTALE was developed using an existential framework; thus, the basic existential concerns of identity (self), isolation (social), meaning, and death were incorporated into the measure. A fifth existential concern, freedom, was not part of the measure. It is possible that there is an AM function related to freedom. For example, for those who are survivors of the Holocaust, Stalin's Gulag, Mao's Cultural Revolution or those entangled in the Israeli-Palestinian conflict, freedom has been elusive and, therefore, may be a central aspect of their AM. On the other hand, for those who have lived relatively free of repressive governments, like the United States, the concept of freedom, the right to choose and to self-determination, has been regarded as a fundamental right, and, therefore, a central aspect of one's identity (Markus \& Kitayama, 1991). Thus, future research may want to consider whether freedom is a functional component of AM and, if it is, is it part of the self function or can it be empirically identified as a separate function.

Earlier it was suggested that future research should consider larger more diverse samples when empirically testing the structure of AM. Although this makes statistical sense, it is also possible that using large cross-sectional samples may hide potential regional or cohort differences in AM. For example, it is possible that there may be functions of AM that are relatively stable and invariant across samples, like the social function. However, it is also possible that the structure and function of AM may vary based on the experiences of particular groups. These are possibilities that can be considered when examining functions of AM.

\section{Conclusion}

The present study has provided a number of unique contributions to the AM literature. First, the TALE was replicated and some support was found for its 3-part structure. Second, an alternative measure to the TALE was developed, the RTALE, based on an existential framework that suggested that the functional components of AM may interact and support one another through relational structures that seek to create a coherent life story by creating meaning in response to uncertainty reduction. As part of the RTALE, two additional functions of AM were proposed: self-esteem and mortality salience. Self-esteem was subsumed by the self-function; mortality salience was a separate function. Empirical support was found for the 4-part structure of the RTALE. Finally, new directions for research were identified. In sum, the present research provides: 1) further empirical support for the self, directive, and social functions of $\mathrm{AM} ; 2$ ) an alternative interpretation of the TALE and a supporting measure; and 3) additional understanding of some of the psychological mechanisms the serve AM, namely, meaning making and uncertainty reduction.

\section{REFERENCES}

Barclay, C. R. (1995). Autobiographical remembering: Narrative constraints on objectified selves. In D. C. Rubin (Ed.), Remembering our past: Studies in autobiographical memory (pp. 94-125). Cambridge: Cambridge University Press.

Baumeister, R. F., Campbell, J. D., Krueger, J. I., \& Vohs, K. D. (2003). Does high self-esteem cause better performance, interpersonal success, happiness, or healthier lifestyles? Psychological Science in the Public Interest, 4, 1-44. doi:10.1111/1529-1006.01431

Baumeister, R. F., Smart, L., \& Boden, J. M. (1996). Relation of threatened egotism to violence and aggression: The dark side of high self-esteem. Psychological Review, 103, 5-33. doi:10.1037/0033-295X.103.1.5

Baumeister, R. F., Tice, D. M., \& Hutton, D. G. (1989). Self-presentation motivations and personality differences in self-esteem. Journal of Personality, 57, 547-579. doi:10.1111/j.1467-6494.1989.tb02384.X

Binswanger, L. (1958). The case of Ellen West. In R. May, E. Angel, \& H. F. Ellenberger (Eds.), Existence (pp. 237-364). New York: Basic.

Binswanger, L. (1963). Being-in-the-world: Selected papers of Ludwig Binswanger. New York: Basic Books.

Bluck, S., Alea, N., Habermas, T., \& Rubin, D. (2005). A tale of three functions: The self-reported uses of autobiographical memory. Social Cognition, 23, 91-117. doi:10.1521/soco.23.1.91.59198

Brewer, W. F. (1986). What is autobiographical memory? In D. C. Rubin (Ed.), Autobiographical memory (pp. 25-49). Cambridge: Cambridge University Press. doi:10.1017/CBO9780511558313.006

Bruner, J. S., \& Postman, L. (1949). On the perception of incongruity: A paradigm. Journal of Personality, 18, 206-223. doi:10.1111/j.1467-6494.1949.tb01241.x

Camus, A. (1955). An absurd reasoning. The myth of Sisyphus and other essays. New York: Vintage

Cohen, G. (1998). The effects of aging on autobiographical memory. In C. P. Thompson, D. J. Herrmann, D. Bruce, D. J. Read, D. G. Payne, \& M. P. Toglia (Eds.), Autobiographical memory: Theoretical and applied perspectives (pp. 105-123). Hillsdale, NJ: Lawrence Erlbaum Associates.

Cohen, J., \& Cohen, P. (1983). Applied multiple regression/correlation analysis for the behavioral sciences. Hillsdale, NJ: Lawrence Erlbaum Associates.

Conway, M. A. (2003). Commentary: Cognitive-affective mechanisms and process in autobiographical memory. Memory, 11, 217-224. doi: $10.1080 / 741938205$

Dunning, D. (2003). The zealous self-affirmer: How and why the self lurks so pervasively behind social judgments. In S. J. Spencer, S. Fein, \& M. P. Zanna (Eds.), Motivated social perception: The Ontario symposium (pp. 45-72). Mahwah, NJ: Lawrence Erlbaum Associates, Inc.

Festinger, L. (1957). A theory of cognitive dissonance. Stanford, CA: Stanford University Press.

Fivush, R. (1998). The functions of event memory: Some comments on Nelson Barsalou. In U. Neisser, \& E. Winograd (Eds.), Remembering reconsidered: Ecological and traditional approaches to the study of memory (pp. 277-282). Cambridge: Cambridge University Press.

Gray, J. A., \& McNaughton, N. (2000). The neuropsychology of anxiety: An enquiry into functions of the septo-hippocampal system. Oxford: Oxford University Press.

Habermas, T., \& Bluck, S. (2000). Getting a life: The emergence of the life story in adolescence. Psychological Bulletin, 126, 748-769. doi:10.1037/0033-2909.126.5.748

Heidegger, M. (1953/1996). Being and time. New York: State University of New York Press.

Heine, S. J., Proulx, T., \& Vohs, K. D. (2006). The meaning maintenance model: On the coherence of social motivations. Personality and Social Psychology Review, 10, 88-110. doi:10.1207/s15327957pspr1002_1

Hyman, I. E., \& Faries, J. M. (1992). The functions of autobiographical memory. In M. A. Conway, D. C. Rubin, H. Spinnler, \& J. W. A. Wagenar (Eds.), Theoretical perspectives on autobiographical memory (pp. 207-221). The Netherlands: Kluwer Academic.

James, W. (1890). The principles of psychology. New York: Holt. doi:10.1037/11059-000

Judge, T. A., \& Ilies, R. (2002). Relationship of personality to performance motivation: A meta-analytic review. Journal of Applied 


\section{O. J. OLIVARES}

Psychology, 87, 797-807. doi:10.1037/0021-9010.87.4.797

Kahneman, D., \& Tversky, A. (1973). On the psychology of prediction. Psychological Review, 80, 237-251. doi:10.1037/h0034747

Koole, S. L., Greenberg, J., \& Pyszczynski, T. (2006). Introducing science to the psychology of the soul. Current Directions in Psychological Science, 15, 212-216. doi:10.1111/j.1467-8721.2006.00438.x

Lazarus, R. S., Averill, J. R., \& Opton, E. M. Jr. (1970). Toward a cognitive theory of emotion. In M. Arnold (Ed.), Third international symposium on feelings and emotions. New York: Academic Press.

Locke, E. A., \& Latham, G. P. (2002). Building a practically useful theory of goal setting and task motivation. American Psychologist, 57, 705-717. doi:10.1037/0003-066X.57.9.705

Lockhart, R. S. (1989). Consciousness and the function of remembered episodes. In H. L. Roediger, \& F. I. M. Craik (Eds.), Varieties of memory and consciousness (pp. 423-430). Hillsdale, NJ: Erlbaum.

Markus, H. R., \& Kitayama, S. (1991). Culture and the self: Implications for cognition, emotion, and motivation. Psychological Review, 98, 224-253. doi:10.1037/0033-295X.98.2.224

McGregor, I. (2006). Offensive defensiveness: Toward an integrative neuroscience of compensatory zeal after mortality salience, personal uncertainty, and other poignant self-threats. Psychological Inquiry, 17, 299-308. doi:10.1080/10478400701366977

McLean, K. C. (2005). Late adolescent identity development: Narrative meaning making and memory telling. Developmental Psychology, 41, 683-691. doi:10.1037/0012-1649.41.4.683

Monat, A., Averill, J. R., \& Lazarus, R. S. (1972). Anticipatory stress and coping reactions under various conditions of uncertainty. Journal of Personality and Social Psychology, 24, 237-253. doi:10.1037/h0033297

Pasupathi, M. (2001). The social construction of the personal past and its implications for adult development. Psychological Bulletin, 127, 651-672. doi:10.1037/0033-2909.127.5.651

Pasupathi, M. (2003). Emotion regulation during social remembering: Differences between emotions elicited during an event and emotions elicited when talking about it. Memory, 11, 151-163. doi:10.1080/741938212

Pasupathi, M., Lucas, S., \& Coombs, A. (2002). Conversational functions of autobiographical remembering: Long-married couples talk about conflicts and pleasant topics. Discourse Processes, 34, 163192. doi:10.1207/S15326950DP3402_3

Pasupathi, M., Mansour, E., \& Brubaker, J. R. (2007). Developing a life story: Constructing relations between self and experience in autobiographical narratives. Human Development, 50, 85-110. doi:10.1159/000100939

Pillemer, D. (2001). Momentous events in the life story. Review of General Psychology, 5, 123-134. doi:10.1037/1089-2680.5.2.123

Pillemer, D. (2003). Directive functions of autobiographical memory: The guiding power of specific episodes. Memory, 11, 193-202. doi:10.1080/741938208

Pinel, E. C., Long, A. E., Landau, M. J., Alexander, K., \& Pyszczynski, T. (2006). Seeing I to I: A pathway to interpersonal connectedness.
Journal of Personality and Social Psychology, 90, 243-257. doi:10.1037/0022-3514.90.2.243

Rentfrow, P. J., Gosling, S. D., \& Potter, J. (2008). A theory of emergence, persistence, and expression of geographic variation in psychological characteristics. Perspectives on Psychological Science, 3, 339-369. doi:10.1111/j.1745-6924.2008.00084.x

Rogers, C. R. (1980). A way of being. Boston: Houghton Mifflin.

Rosenberg, M. (1965). Society and the adolescent self-image. Princeton, NJ: Princeton University Press.

Schwandt, D. R. (2005). When managers become philosophers: Integrating learning with sensemaking. Academy of Management Journal, 4, 176-192.

Smith, J. R., Hogg, M. A., Martin, R., \& Terry, D. J. (2007). Uncertainty and the influence of group norms in the attitude-behavior relationship. British Journal of Social Psychology, 46, 769-792. doi:10.1348/014466606X164439

Swann, W. B. Jr. (1987). Identity negotiation: Where two roads meet. Journal of Personality and Social Psychology, 53, 1038-1051. doi:10.1037/0022-3514.53.6.1038

Swann, W. B., \& Hill, C. A. (1982). When our identities are mistaken: Reaffirming self-conceptions through social interaction. Journal of Personality and Social Psychology, 43, 59-66. doi:10.1037/0022-3514.43.1.59

Swann, W. B. Jr., Pelham, B. W., \& Krull, D. S. (1989). Agreeable fancy or disagreeable truth? Reconciling self-enhancement and selfverification. Journal of Personality and Social Psychology, 57, 782791. doi:10.1037/0022-3514.57.5.782

Tabachnick, B. G., \& Fidell, L. S. (2007). Using multivariate statistics. Boston, MA: Pearson.

Walker, W. R., Skowronski, J. J., Gibbons, J. A., \& Vogl, R. J. (2003). Why people rehearse their memories: Frequency of uses and effects on the intensity of emotions associated with autobiographical memories. Manuscript submitted for publication.

Webster, J. D. (1993). Construction and validation of the reminiscence functions scale. Journal of Gerontology, 48, 256-252.

Webster, J. D. (1998). Attachment styles, reminiscence functions, and happiness in young and elderly adults. Journal of Aging Studies, 12, 315-330. doi:10.1016/S0890-4065(98)90006-8

Webster, J. D., \& McCall, M. E. (1999). Reminiscence functions across adulthood: A replication and extension. Journal of Adult Development, 6, 73-85. doi:10.1023/A:1021628525902

Wilson, A. E., \& Ross, M. (2003). The identity function of autobiographical memory: Time is on our side. Memory, 11, 137-149. doi:10.1080/741938210

Woike, B., Mcleod, S., \& Goggin, M. (2003). Implicit and explicit motives influence accessibility to different autobiographical knowledge. Personality and Social Psychology Bulletin, 29, 1046, 1055.

Yost, J. H., Strube, M. J., \& Bailey, J. R. (1992). The construction of the self: An evolutionary view. Current Psychology: Research \& Reviews, 11, 110-121. 